\title{
INVESTIGATION OF STRESS CORROSION CRACKING IN MAGNESIUM ALLOYS BY QUANTITATIVE FRACTOGRAPHY METHODS
}

\begin{abstract}
The article shows that the use of quantitative fracture description may lead to significant progress in research on the phenomenon of stress corrosion cracking of the WE43 magnesium alloy. Tests were carried out on samples in air, and after hydrogenation in $0.1 \mathrm{M} \mathrm{Na}_{2} \mathrm{SO}_{4}$ with cathodic polarization. Fracture surfaces were analyzed after different variants of the Slow Strain Rate Test. It was demonstrated that the parameters for quantitative evaluation of fracture surface microcracks can be closely linked with the susceptibility of the WE43 magnesium alloy operating under complex state of the mechanical load in corrosive environments. The final result of the study was the determination of the quantitative relationship between Slow Strain Rate Test parameters, the mechanical properties, and the parameters of the quantitative evaluation of fracture surface (microcracks).

Keywords: hydrogen, cracking, SCC, magnesium alloys
\end{abstract}

\section{Introduction}

Magnesium alloys are characterized by the lowest density of all metallic structural materials and display good mechanical properties. Therefore, they are widely used in automotive and aerospace industries. However, magnesium alloys show very poor corrosion resistance, even in dilute electrolyte solutions [1]. Structural components made of magnesium alloys are often subjected to mechanical load and corrosive environment simultaneously. As a result, the stress corrosion cracking (SCC) may appear. Initiation and advancement of SCC is very difficult to detection, although it leads to essential microstructural changes. Material failure during stress corrosion displays no significant indications, especially in initial stages and advancement of micro cracking [2]. SCC of magnesium alloys is extremely dangerous in hydrogen containing environments, even at very low concentration $[3,4]$. However, it should be note that in case of Mg-Y-RE alloys intended for elevated temperature applications, there are very poor literature data concerning their susceptibility to SCC in hydrogen containing environments.

Basic examination for evaluation of susceptibility to SCC is slow strain rate testing (SSRT) in electrolyte solution [5-7]. The basis for these tests is a slow increase of the applied load until rupture of the sample, thus incorporating the time component in the test. Basic parameters determined from SSRT ( $\varepsilon-$ unit strain (\%), UTS - Ultimate Tensile Strength (MPa), Z - necking $(\%), t$ - time to fracture $(\mathrm{h}))$ characterize reaction of material in corrosive environment. An important complement to mechanical tests is a quantitative fractography. Analysis of mechanical properties results combined with quantitative fractography allows to obtain some new information about material failure during destruction processes [8-11].

A variety of different experimental techniques have been developed in the past to study fracture surfaces [12]. The details of these techniques, their advantages and limitations, are discussed in some detail by Undervood [13], Wrigth and Karlsson [14], Coster and Chermant [15], and Undervood and Banerji [16]. Generally in a broad sense, the basic approaches can be categorized into two groups:

- methods based on images of the fracture surface, i.e. quantitative description of the fracture surface,

- methods based on metallographic cross-sections of the fracture surface, i.e. profilometric analysis.

Each of the quantitative descriptions of the fracture surface is characterized by a limited experimental capabilities. In practice, depending on the morphology of the fracture and the possibility of testing were used for both approaches. The authors of this publication have used both techniques - quantitative description of the fracture surface $[10,11]$ or a profile fracture (linear roughness index $R_{L}$, fractal dimension $D_{F}$ and overlap index $O_{L}$ ) [8,9].

But in order to use the possibilities of this combined method (mechanical properties results combined with quantitative fractography) to comprehensive material (WE43 magnesium alloy) description during SCC (stress corrosion cracking), some methodical problems should be solved. The main problem was development of methodology allowing quantitative fracture surface evaluation. In particular, correct selection of an object characterizing the SCC was crucial.

\footnotetext{
SILESIAN UNIVERSITY OF TECHNOLOGY INSTITUTE OF MATERIALS SCIENCE, FACULTY OF MATERIALS ENGINEERING AND METALLURGY, 8 KRASIŃSKIEGO STR.,40-019 KATOWICE, POLAND

\# Corresponding author: maria.sozanska@polsl.pl
} 
This paper shows an original method of fracture surface imaging, using the image analysis with the micrograph from scanning electron microscope (SEM) as input image. The analysis subject was the quantitative evaluation of SCC for WE43 magnesium alloy after different variants of mechanical load and corrosive environment using SSRT and quantitative fractography.

\section{Materials and methods}

The material used in this study was WE43 magnesium alloy in form of extruded rods with the following chemical composition (wt. \%): $\mathrm{Mg}$ - balance, $\mathrm{Y}-4.1, \mathrm{RE}-4.0, \mathrm{Zr}-0.5$. SSRTs were performed using testing machine according to PN-EN ISO 7539-7 standard. In all cases the identical strain rate equal to $9 \cdot 10^{-7} \mathrm{~s}^{-1}$ was applied. Mechanical tests were carried out using cylindrical samples with gauge diameter of $5.0 \mathrm{~mm}$ and gauge length of $20.0 \mathrm{~mm}$. SSRTs were performed in three variants:

- $\quad$ 1st variant - SSRT in air;

- 2nd variant - SSRT in air after hydrogenation under cathodic polarization for 24 hours in $0.1 \mathrm{M} \mathrm{Na}_{2} \mathrm{SO}_{4}$ solution (current density $i_{c}=50 \mathrm{~mA} / \mathrm{cm}^{2}$ );

- 3rd variant - SSRT during simultaneous hydrogenation under cathodic polarization $0.1 \mathrm{M} \mathrm{Na}_{2} \mathrm{SO}_{4}$ solution (current density $i_{c}=50 \mathrm{~mA} / \mathrm{cm}^{2}$ ).

As a result, tensile curves were obtained. Four basic parameters $(\varepsilon$, UTS, $Z, t)$ were determined from these curves.

Fractographic investigation were performed using Hitachi S-3400N SEM and Met-Ilo ${ }^{\circledR}$ image analysis software. Sample preparation for SEM investigations after SSRT involved ultrasonic cleaning in acetone in 5 minutes.
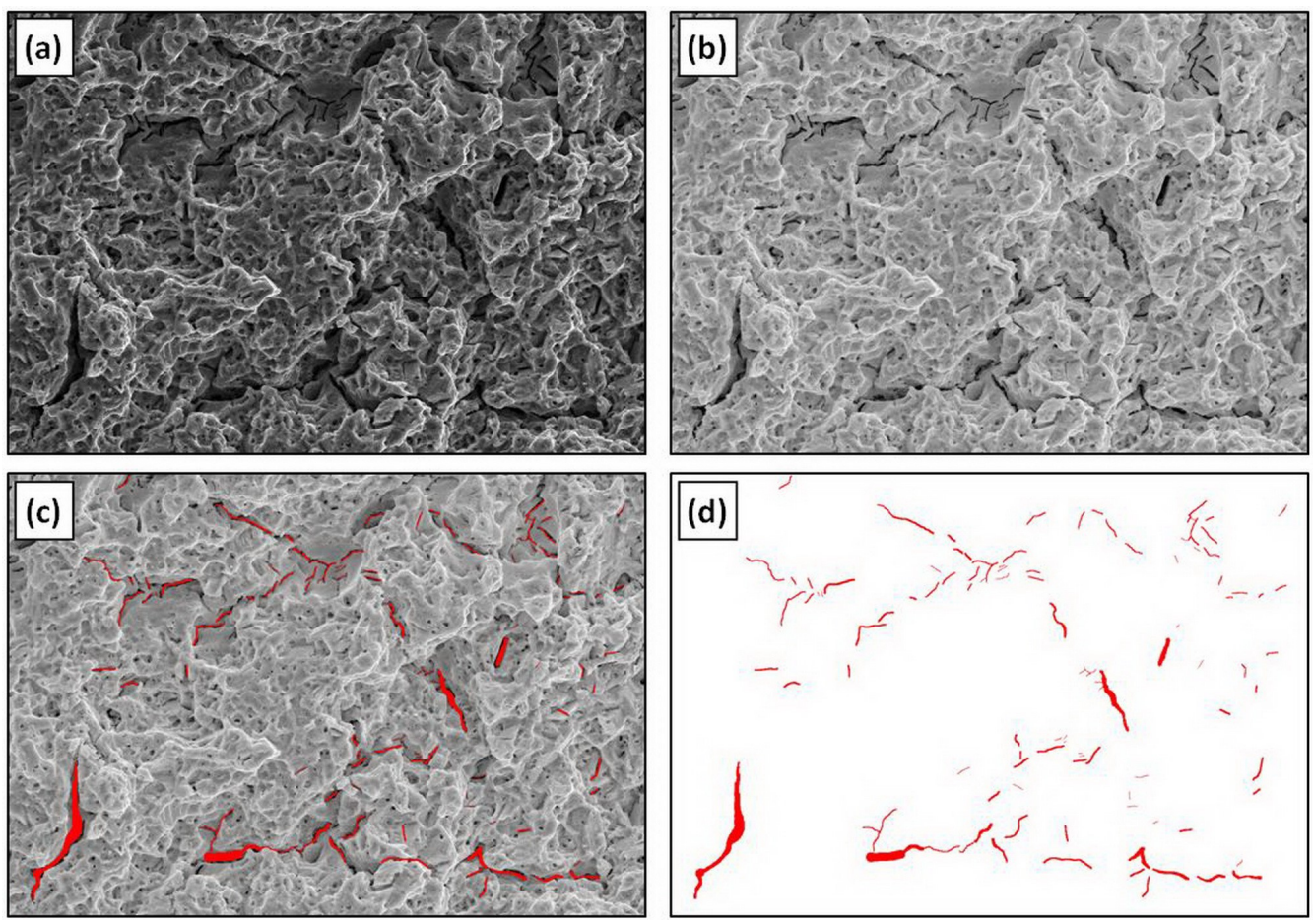

Fig. 2. Procedure of manual cracks detection on the fracture image: (a) reading in an image intended for analysis; (b) brightness and contrast correction for cracks revealing; (c) manual cracks detection ; (d) saving the binary image
An original method of quantitative fractography consists of the following stages:

1) the whole fracture surface was took into consideration especially evaluation of cracks on fracture surface as an important feature;

2) input images for quantitative fractography were high resolution (HR) fracture micrographs, obtained by merging together of many SEM images involving the whole fracture surface (Fig. 1). Application of HR images of the whole fracture surface allowed to detect of all small cracks;

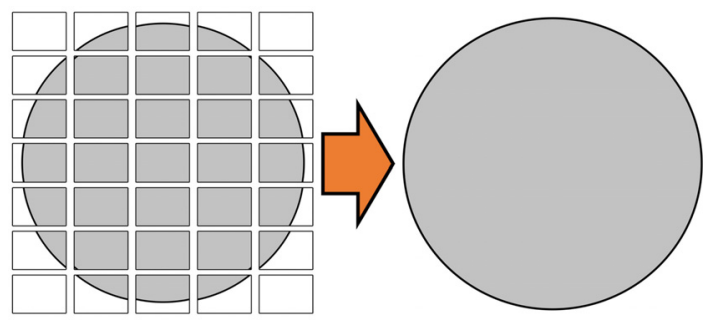

Fig. 1. Scheme of HR image preparation for quantitative fractography

3) cracks detection of the fracture surface. Due to very low diversification of gray scale level between cracks and remain fracture area, an automatic detection was not possible. A manual detection using the GIMP software was applied and it consists o four stages: (i) a reading in of HR image to the software; (ii) correction of brightness and contrast in order to emphasize of cracks on fracture surface; (iii) a manual detection of cracks on fracture surface; (iv) saving a binary image of cracks. Each stage of mentioned procedure is shown in Fig. 2. 
4) binary images were intended for quantitative analysis using the Met-Ilo ${ }^{\circledR}$ software. Image analysis involved: counting of cracks number on fracture surface and measurement of cracks dimensions - length and width (min., max., average). The spacing between neighboring cracks were analysed too.

\section{Results and discussion}

Evaluation of mechanical properties of WE43 alloy during $S C C$

Evaluation of simultaneous interaction of mechanical load and corrosive environment on WE43 alloy was performed on the basis of SSRT. Results of these investigation were shown in Fig. 3 and in Table 1.

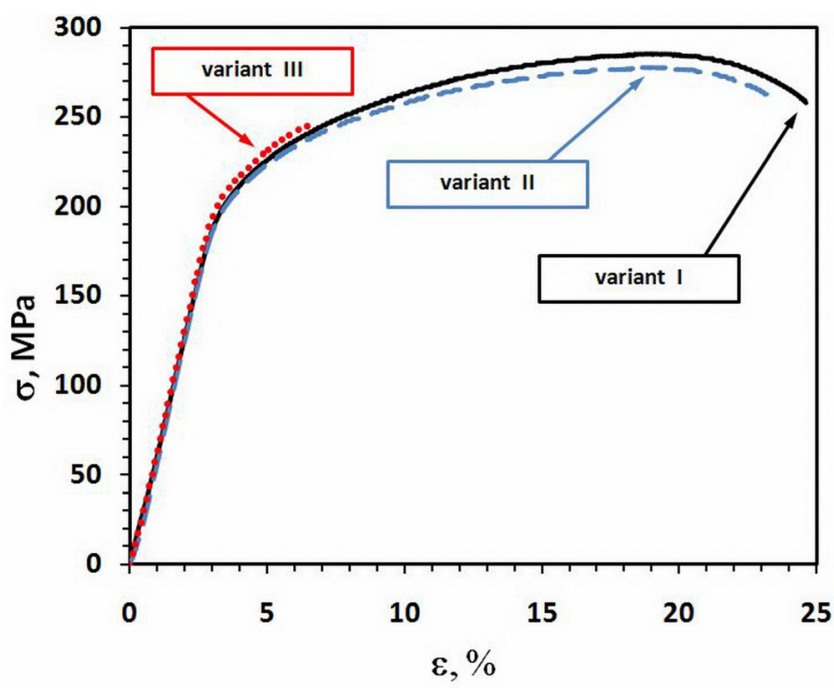

Fig. 3. Tensile curves for WE43 alloy obtained from SSRT

Obtained results reveal that mechanical properties strongly decreased in case of the 3 rd variant of SSRT in comparison to the 1st variant (strain in air): UTS decreased from $283 \mathrm{MPa}$ to $244 \mathrm{MPa}$, unit elongation decreased from $24.6 \%$ to $7 \%$ and necking decreased from $39.2 \%$ to $11.6 \%$. Time to rupture shortened
TABLE 1

Results of three variants of SSRT for WE43 alloy

\begin{tabular}{|c|c|c|c|c|}
\hline \hline SSRT variant & $\boldsymbol{\varepsilon}, \boldsymbol{\%}$ & $\boldsymbol{Z}, \boldsymbol{\%}$ & UTS, MPa & $\boldsymbol{t}$, hours \\
\hline 1st variant & 24.6 & 39.2 & 283 & 73.1 \\
\hline 2nd variant & 23.4 & 31.1 & 278 & 73.7 \\
\hline 3rd variant & 7.0 & 11.6 & 244 & 22.2 \\
\hline
\end{tabular}

about three times in comparison to SSRT in air (from $73.1 \mathrm{~h}$ to $22.2 \mathrm{~h}$ ). In case of the 2 nd variant of SSRT only the necking decreased from $39.2 \%$ to $31.1 \%$ in comparison to 1 st variant. Other parameters ( $\varepsilon$, UTS, $t$ ) were comparable to the 1 st variant of SSRT.

Quantitative evaluation of fracture morphology after SSRT

Comparison of SEM micrographs after 1st and 2nd variants of SSRT reveal significant changes in their morphology. In case of sample strained in air (1st variant) SEM observations reveal ductile fracture (Fig. 4).

However in case of sample strained during cathodic polarization (3rd variant), fracture morphology changed from ductile to brittle with many micro cracks (Fig. 5).

Sample strained in air after hydrogenation (2nd variant) was characterized by complex fracture morphology: the fracture was mainly ducile, but there were some brittle areas with cracks (Fig. 6). However, the number of cracks was much lower in comparison to 3rd variant of SSRT.

Binary images of cracks on fracture surfaces (Fig. 7-9) intended for quantitative analysis and their results (Table 2) reveal significant differences between all samples.

Examination of sample strained in air reveals only few randomly spaced cracks on fracture surface (about 17) - Fig. 7. Maximal size of these cracks was $51 \mu \mathrm{m}$ in length and $1.6 \mu \mathrm{m}$ in width. Sample after 3rd variant of SSRT was characterized by the highest number of cracks (3143), but they were non-uniformly spaced on fracture surface. The highest accumulation of cracks was found in the area between the centre and the edge of the sample (Fig. 9). Probably it was caused by the off-centre setting
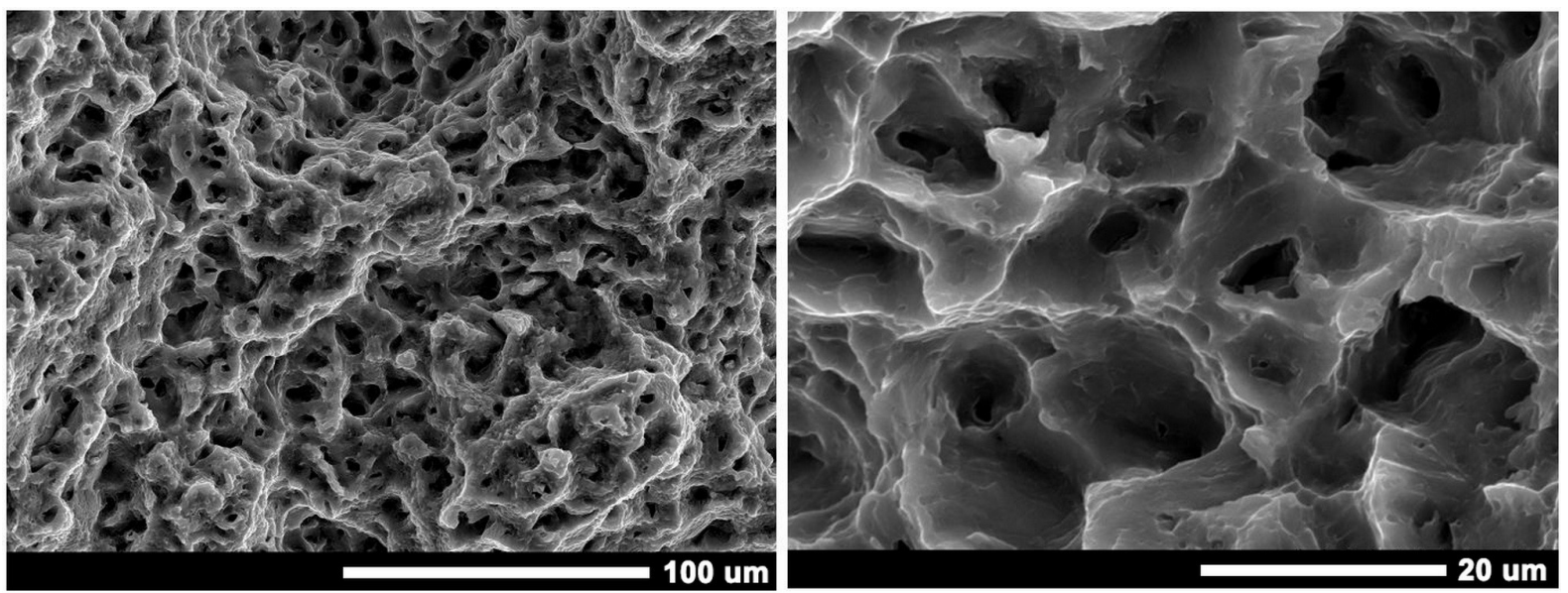

Fig. 4. Fracture morphology of WE43 alloy after SSRT (1st variant) 
560
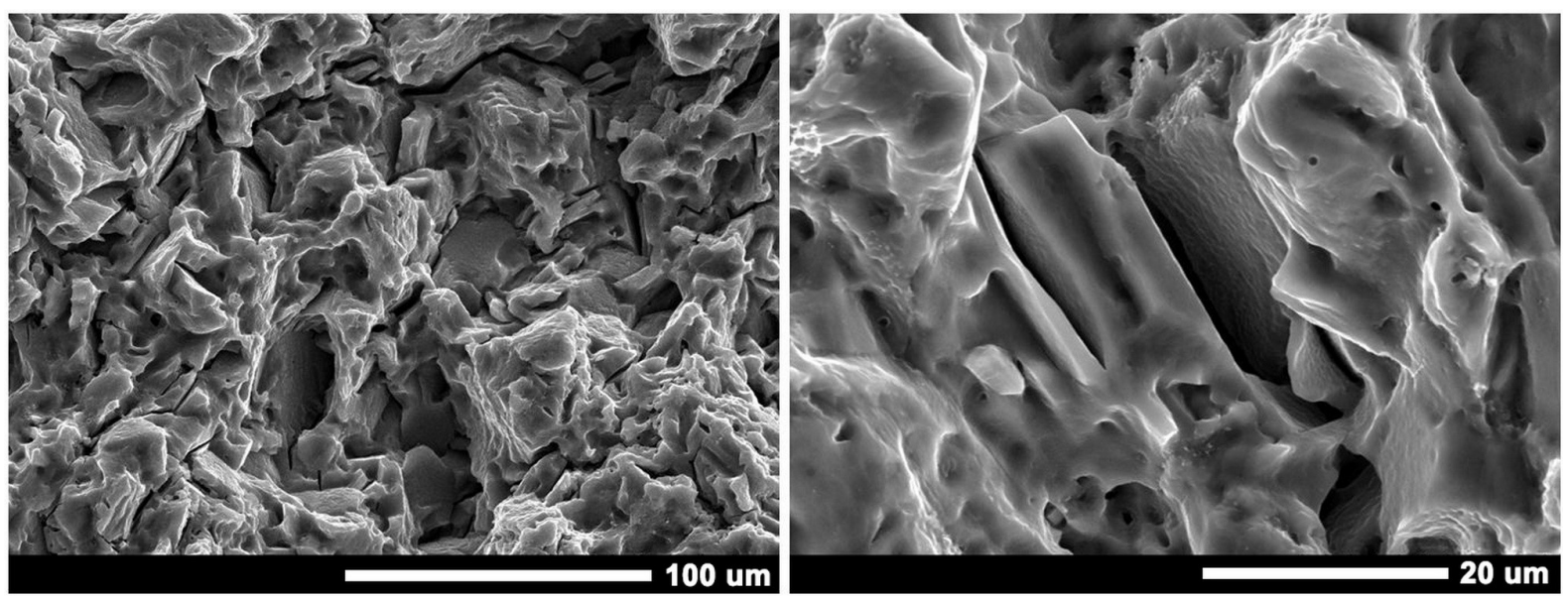

Fig. 5. Fracture morphology of WE43 alloy after SSRT (3rd variant)
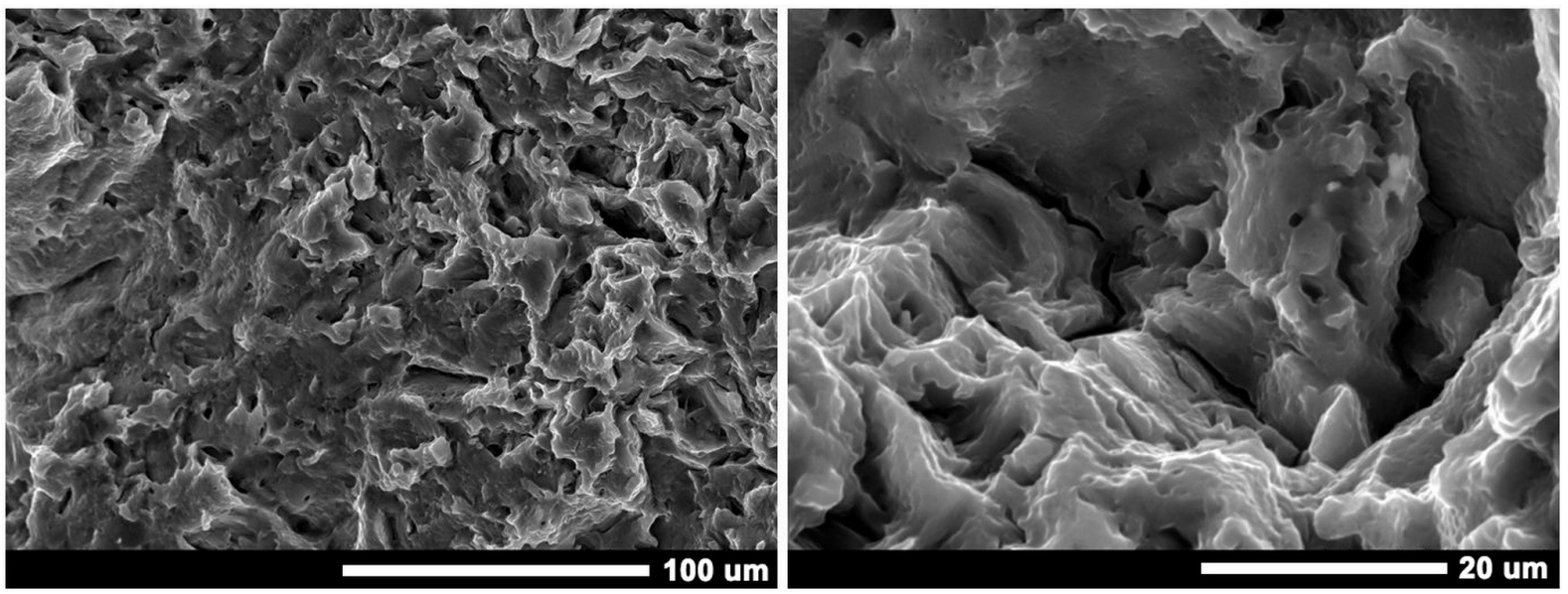

Fig. 6. Fracture morphology of WE43 alloy after SSRT (2nd variant)

TABLE 2 on the sample strained after hydogenation (2nd variant). Cracks

Results of quantitative fractography for WE43 alloy after SSRT

\begin{tabular}{|c|c|c|c|c|c|}
\hline \hline \multirow{2}{*}{$\begin{array}{c}\text { SSRT } \\
\text { variant }\end{array}$} & & $\begin{array}{c}\text { Number } \\
\text { of cracks }\end{array}$ & $\begin{array}{c}\text { Cracks } \\
\text { length, } \\
\boldsymbol{\mu m}\end{array}$ & $\begin{array}{c}\text { Cracks } \\
\text { width, } \\
\boldsymbol{\mu m}\end{array}$ & $\begin{array}{c}\text { Distance be- } \\
\text { tween neigh- } \\
\text { bors, } \boldsymbol{\mu m}\end{array}$ \\
\hline \multirow{2}{*}{$\begin{array}{c}\text { variant } \\
\text { I }\end{array}$} & average & $\mathbf{1 7} \pm \mathbf{0}$ & $\mathbf{2 7 . 9} \pm \mathbf{1 1 . 2}$ & $\mathbf{0 . 8} \pm \mathbf{0 . 2}$ & $\mathbf{3 1 6} \pm \mathbf{3 2 9}$ \\
\cline { 2 - 6 } & min. & 17 & 14.3 & 0.8 & 35 \\
\cline { 2 - 6 } & max. & 17 & 50.8 & 1.6 & 1102 \\
\hline \multirow{2}{*}{$\begin{array}{c}\text { variant } \\
\text { II }\end{array}$} & average & $\mathbf{4 0 9} \pm \mathbf{0}$ & $\mathbf{2 3 . 1} \pm \mathbf{1 7 . 0}$ & $\mathbf{0 . 9} \pm \mathbf{0 . 2}$ & $\mathbf{5 3} \pm \mathbf{5 5}$ \\
\cline { 2 - 6 } & min. & 409 & 8.5 & 0.9 & 8 \\
\cline { 2 - 6 } & max. & 409 & 178.0 & 2.5 & 356 \\
\hline \multirow{2}{*}{$\begin{array}{c}\text { variant } \\
\text { III }\end{array}$} & average & $\mathbf{3 1 4 3} \pm \mathbf{0}$ & $\mathbf{2 3 . 0} \pm \mathbf{1 5 . 5}$ & $\mathbf{1 . 2} \pm \mathbf{0 . 6}$ & $\mathbf{2 8} \pm \mathbf{2 4}$ \\
\cline { 2 - 6 } & min. & 3143 & 5.9 & 1.0 & 5 \\
\cline { 2 - 6 } & max. & 3143 & 294 & 14.7 & 452 \\
\hline \multirow{2}{*}{} & & & & & \\
\hline
\end{tabular}

of tensile bar and cylindrical anode during cathodic polarization. Average length of cracks was similar for all SSRT variants and equal to about $25 \mu \mathrm{m}$. The biggest cracks was observed for sample after 3rd variant of SSRT $(294 \mu \mathrm{m}$ in length and $14.7 \mu \mathrm{m}$ in width). Despite of small differences in mechanical properties between 1st and 2nd variant of SSRT (Table 1), quantitative fractography reveals significant differences (Table 2): there were about 409 cracks (max. length $-178 \mu \mathrm{m}$, max. width $-2.5 \mu \mathrm{m}$ ) were non-uniformly spaced on fracture surface, similar to the fracture after 3 rd variant.

\section{Conclusions}

Obtained results allow to draw the following conclusions:

1) application of quantitative fractography to fracture evaluation after SSRT gives new information about the suscepibility of WE43 alloy to SCC under constant mechanical load;

2) quantitative analysis of cracks on fracture surface is a suitable method allows to evaluation of susceptibility to SCC;

3) results of quantitative fractography are important complement of stress corrosion investigations:

- the highest number of cracks and the lowest mechanical properties were found in case of 3rd variant of SSRT;

- the highest length and width of cracks were found after 3rd variant of SSRT, but the average size of cracks were similar for all variants of SSRT;

- the smallest spacing between neighboring cracks was found for 3rd variant of SSRT; 

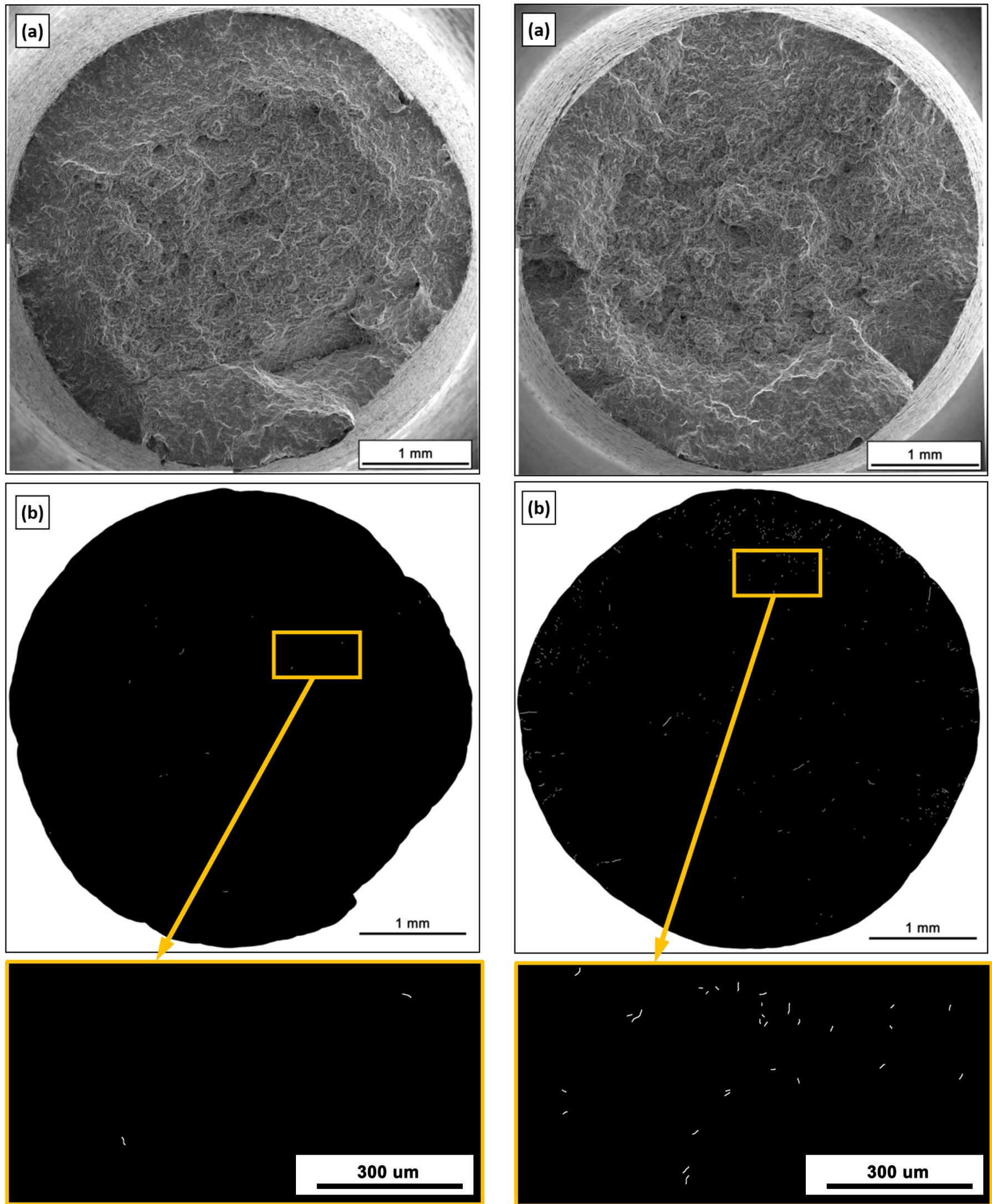

Fig. 7. Fracture morphology of WE43 alloy after 1st variant of SSRT (a) and binary image of cracks on fracture surface (b)

Fig. 8. Fracture morphology of WE43 alloy after 2nd variant of SSRT (a) and binary image of cracks on fracture surface (b) 

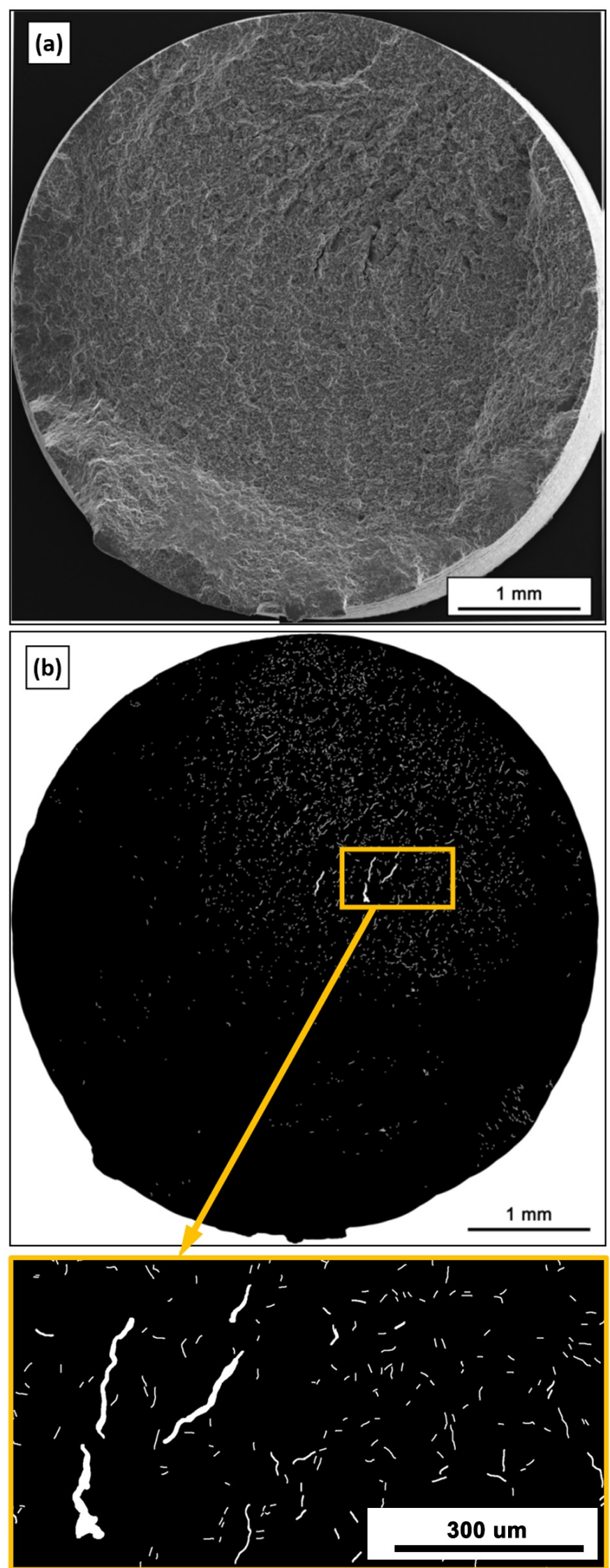

Fig. 9. Fracture morphology of WE43 alloy after 3rd variant of SSRT (a) and binary image of cracks on fracture surface (b)
4) developed method of quantitative fractography seems to be more sensitive to negligible changes of corrosive environment and mechanical load interaction in comparison to SSRT parameters;

5) an important feature of presented method is taking into account the whole fracture area and all cracks with very diversified size.

\section{Acknowledgements}

This work partially was supported by the National Science Centre in Poland under the research grant "Effect of hydrogen on structure and stress corrosion cracking of selected magnesium alloys from Mg-Y-RE-Zr and Mg-Al-RE systems" No. 2011/03/B/ST8/06387.

\section{REFERENCES}

[1] V.S. Raja, T. Shoji, Stress corrosion cracking. Theory and practice, 2011 Woodhead Publishing Limited.

[2] R.G. Song, C. Blawert, W. Dietzel, A. Atrens, Mat. Sci. Eng. A-Struct. 399, 308-317 (2005).

[3] N.Winzer, A. Atrens, W. Dietzel, V.S. Raja, G. Song, K.U. Kainer, Mat. Sci. Eng. A-Struct. 488, 339-351 (2008).

[4] J. Chen, J. Wang, E. Han, J. Dong, W. Ke, Corros. Sci. 50, 12921305 (2008).

[5] ASTM G129, Standard Practice for Slow Strain Rate Testing to Evaluate the Susceptibility of Metallic Materials to Environmentally Assisted Cracking.

[6] ISO 7539-7, Corrosion of metals and alloys - Stress corrosion testing - Part 7: Method for slow strain rate testing.

[7] ASTM F1624, Standard Test Method for Measurement of Hydrogen Embrittlement Threshold in Steel by the Incremental Step Loading Technique.

[8] K. Kłyk-Spyra, M. Sozańska, Mater. Charact. 56, 384-288 (2006).

[9] J. Michalska J., M. Sozańska, M. Hetmańczyk, Mater. Charact. 60, 1100-1106 (2009).

[10] M. Sozańska, J. Sojka, P. Betakova, Mater. Charact. 46, 239-243 (2001).

[11] M. Sozańska, J. Sojka, Inżynieria Materiałowa 4 (164), 247-249 (2008)

[12] B.M Strauss, S.K. Putatunda, Quantitative Methods in Fractography, ASTM, STP 1085, 3-51 (1990)

[13] E.E. Undervood, Quantitative Stereology, 1970 Addison-Wesley Reading MA.

[14] K. Wrigth, B. Karlsson, Topograpic Quantification of Nonplanar Localized Surfaces, Proc. Third European Symp. For Stereology, Ljubljana, 247-253 (1981).

[15] M. Coster, J.L. Chermant, Précis d'Analyse d'Images, 1985 Editions du CNRS, Paris.

[16] E.E. Undervood, K. Banerji, Quantitative Fractography, in: Metals Handbook, 9th Edition, vol. 12, Fractography, ASM International 1987. 